\title{
Vilèm Flusser: crítica estética e imagen tecno-visual.
}

\author{
Víctor Silva Echeto
}

Resumen: El giro estético de la ilustración se debe, fundamentalmente, a Kant y a Hegel. En ese contexto, el concepto de imagen visual emerge, atrapando al arte en las redes estéticas. La modernidad, en esa época, adquiere toda su madurez y habilita un giro, en la filosofía, occidental, que estetiza la razón. Radicalizado el giro, en el llamado postestructuralismo, es Vilém Flusser, quien, desde su nomadismo e indisciplinamiento, plantea una radical crítica al pensamiento hegeliano, desde "la imagen técnica" como "elogio de la superficialidad", o, en nuestro parecer, "teoría de la pantalla". Los intermedios y posteriores planteamientos críticos en crisis, deconstructivos, fundamentalmente, en el caso de Derrida, desestabilizan y tensionan, el planteamiento estético, desde los márgenes (párergon) y la interrogante por "la verdad" de lo visual. La postestética, tanto en Badiou como en Rancière, se pregunta en un caso (Badiou) por lo inestético y, en el otro (Rancière), por el reparto de lo sensible. El presente texto, analiza, desde la crítica a la estética, tanto en Kant como en Hegel, el giro visual en Flusser, la deconstrucción y el giro de los llamados postalthusserianos (Badiou y Rancière), y la implicancia de la imagen técnica que, desde lo superficial y lo profundo, permiten delinear los trazos de una teoría de la pantalla.

Palabras- clave: imagen tecno visual; pantalla; Vilèm Flusser; posthegelianismo.

Abstract: Vilém Flusser: aesthetic criticism and technovisual images - The aesthetic shift in art is ascribed mainly to Kant and Hegel. In this context, the concept of visual image emerges, ensnaring art in the meshes of aesthetics. At that time, modernity reaches full maturity, enabling a shift in Western philosophy that aestheticizes reason. This shift is radicalized in so-called post-structuralism, and it is Vilém Flusser, with his nomadic and undisciplined nature, who introduces a radical critique of Hegelian thought, based on the "technical image" as "praise of superficiality" or, in our view, as "screen theory." The intervening and subsequent critical approaches in deconstructive crisis, fundamentally in the case of Derrida, destabilize and expand the aesthetic approach, starting from the boundaries (parergon) and the questioning of the "truth" of the visual. Post-aesthetics, in both Badiou and Rancière, questions the unaesthetic (Badiou) on the one hand, and the divide of the sensitive (Rancière) on the other. This text analyzes critique and aesthetics in both Kant and Hegel, the visual shift in Flusser, the deconstruction and shift of the so-called post-Althusserians (Badiou and Rancière), and the implication of the technical image, which, from the superficial to the deep, enables us to delineate the outlines of a screen theory.

Keywords: technovisual image display; Vilém Flusser; post-Hegelianism 


\section{Introducción por la estética. La recuperación del hegelianismo de izquierdas}

El giro estético de la ilustración se debe, fundamentalmente, a Kant y a Hegel. En ese contexto, el concepto de imagen visual emerge, atrapando al arte en las redes estéticas. La modernidad, en esa época, adquiere toda su madurez y habilita un giro, en la filosofía, occidental, que estetiza la razón.

La recuperación de Hegel, en la modernidad tardía, se debe a otro de los giros estéticos que se producen en Alemania, como fue el generado por el Instituto de Investigaciones Sociales. Tanto Horkheimer como Adorno, luego de su vinculación con la filosofía kantiana, producirán un rodeo en la filosofía hegeliana matizándolo con la fenomenología, el postmarxismo, el psicoanálisis, entre otros movimientos que serán incorporados por los frankfurtianos.

Las preocupaciones iniciales de Horkheimer y Adorno están más cercanas a la crítica kantiana, su alejamiento de ésta se produce en su relectura de Hegel. Entre los antecedentes se encuentra la tesis doctoral de Horkheimer sobre Kant concluida en 1922, y sus primeros cursos como Privatdozent en mayo de 1925, sobre Kant y Hegel (Jay, 2008: p. 43).

Adorno, por su parte, se había pasado -en su juventud- más de un año junto con Kracauer, estudiando la Crítica de la razón pura de Kant. No obstante, hay que reconocer, que mientras los hegelianos de izquierda habían sido los sucesores inmediatos de los idealistas clásicos alemanes, el Instituto de Investigaciones Sociales matizará sus lecturas de Kant y Hegel con Schopenhauer, Nietzsche, Bergson, Weber, Husserl, Freud, incluyendo, además, la sistematización que realizan del propio marxismo.

Es Husserl, a su vez, para Foucault (1995: p. 10), uno de los límites que cruzan unos y otros hegelianos de izquierda, entre ellos, los integrantes del Instituto de Investigaciones Sociales. "Por tomar como ejemplo el que, sin duda, de todos fue el más alejado de lo que podríamos denominar una crítica de izquierda, no hay que olvidar que Husserl en 1936 refería la crisis contemporánea de la humanidad europea a algo que tenía que ver con las relaciones entre el conocimiento y la técnica, la episteme y la techné". En un gesto poco habitual en él' ${ }^{1}$, Foucault reconoce que vincular Marx a Husserl, también, se producirá en Francia, gracias a la influencia del Instituto de Investigaciones Sociales. Es decir, a diferencia de Alemania, la atención por la Aufklärung (ilustración) será tardía en Francia. No obstante, la actitud -desde la segunda mitad del siglo XX, producto, entre otros fenómenos, de la influencia de la fenomenología- cambiará. En términos de Foucault: "la situación en Francia ha cambiado en los últimos años" y "puede ser retomada en una vecindad bastante significativa con la Escuela de Frankfurt. Se ha planteado desde la fenomenología", con

1 Hay que recordar las escasas menciones que Foucault realiza de los integrantes del Instituto de Investigaciones Sociales. Se reconoce un tardío conocedor de la obra de Horkheimer y de Adorno. En menor medida se percibe que conoce la obra de W. Benjamin, extremo al que llega al definir la actitud de la modernidad como la pendular oscilación entre Kant y el flaneur. Este último ya había sido destacado, por W. Benjamin en su análisis de la modernidad París en el siglo XIX, al que no cita Foucault. 
la importancia del concepto de sentido. “¿Cómo puede ser que haya sentido a partir del sinsentido? (...) ¿cómo puede ser que la racionalización conduzca al furor del poder?". Es interesante como esta frase se vincula con el primer Deleuze, el de Lógica del sentido (1996), y con la deconstrucción del sentido que radicaliza Jacques Derrida, en "Firma, acontecimiento y contexto" publicado en Márgenes de la filosofía (1989).

Como resultado de ello, la teoría crítica del Instituto de Investigaciones Sociales, tuvo que afirmarse contra una profusión de corrientes que habían alejado a Hegel de ese campo. Aunque, no puede dejar de sufrir la influencia de algunas de sus ideas. No obstante, entre una Alemania de preguerra y una de postguerra, el Instituto de Investigaciones Sociales fue testigo de muchos de esos cambios.

Los hegelianos de izquierda escribieron en un país, como fue el caso de Alemania, que comenzaba a sentir los efectos de la modernización capitalista. En la época de la teoría crítica, el capitalismo occidental, teniendo en Alemania uno de sus principales representantes, había ingresado en una etapa cualitativamente nueva, dominada por monopolios crecientes y por una intervención gubernamental cada vez mayor en la economía.

En resumen, mientras que la primera generación de teóricos críticos de la década de 1840 presenta una crítica "inmanente" de la sociedad, basada en la existencia de un "sujeto" histórico real, la que se inicia en el siglo XX, ve renacer la teoría crítica pero cada vez más forzada a una posición de "trascendencia", por el debilitamiento de la clase trabajadora revolucionaria (Jay, 2008: p. 85).

Horkheimer, en 1937, cuando asume la dirección del Instituto de Investigaciones Sociales, está directamente influenciado por Hegel y Marx. En ese año publicará: "Teoría crítica y teoría tradicional", texto- manifiesto que marca las proyecciones del Instituto de Investigaciones Sociales y sus críticas.

En ese escrito, Horkheimer entiende el comportamiento "crítico", no "tanto en el sentido de la crítica idealista de la razón pura", sino "como el de la crítica dialéctica de la economía política". Es decir, "se refiere a una característica esencial de la teoría dialéctica de la sociedad" (Horkheimer, 1974: p. 239). Más que a subsanar inconvenientes, están dirigidos a la construcción de la sociedad en su conjunto. "La separación entre individuo y sociedad, en virtud de la cual el individuo acepta como naturales los límites prefijados a su actividad, es relativizada en la teoría crítica", para la cual "la razón no puede hacerse comprensible a sí misma mientras los hombres actúen como miembros de un organismo irracional. El organismo, como unidad que crece y muere de manera natural, no es precisamente un modelo para la sociedad, sino una sofocante forma de ser, de la cual debe emanciparse" (Horkheimer, 1974: p. 241).

El pensamiento crítico y su teoría se oponen a lo armónico e ilusionista, es decir, no es ni la función de un individuo aislado ni la de una generalidad de individuos, sino que tienen "por sujeto a un individuo determinado en sus relaciones reales con otros individuos y grupos, y en su relación crítica con una determinada clase, y, por último, 
en su trabazón, así mediada, con la totalidad social y la naturaleza". Idealismo que, para Horkheimer, "es ideología en sentido estricto", y es en esa apariencia en la que, desde Descartes, vive ese idealismo.

En Francia, la relación con el hegelianismo es más compleja, debido a la traducción de Hegel que realiza Kojéve y, como a partir de éste, es conocida la obra de Hegel. Desde el curso Introduction à la lecture de Hegel, de 1938- 1939, fue conocida, por muchos teóricos, la obra de Hegel en Francia. Entre los temas centrales de la lectura hegeliana de Kojève, estaba el problema del fin de la historia y de la imagen que el hombre y la naturaleza asumirían en el mundo posthistórico.

Mientras que Althusser se proclama anti-hegeliano, son los intentos de superación del arte de los situacionistas, alrededor de figuras como Guy Debord, los que sostendrán sus tesis sobre bases hegelianas, produciendo un post-hegelianismo de izquierdas. La superación del arte de los situacionistas tiene sus bases en la idea del fin de la historia del arte, de la autoconciencia y de la dialéctica arte-política y arte-sociedad. La crítica a la sociedad del espectáculo debordiana se asoma desde un pronunciado hegelianismo.

\section{La crítica de Vilém Flusser}

Radicalizado el giro, en el Ilamado postestructuralismo, es Vilém Flusser, quien, desde su nomadismo e indisciplinamiento, plantea una radical crítica al pensamiento ilustrado, desde "la imagen técnica" como "elogio de la superficialidad", o, en nuestro parecer, como "teoría de la pantalla".

Flusser entró en el debate sobre las "imágenes técnicas" (2008), sobre la pantalla, puso en cuestionamiento la trascendencia desde el elogio de la superficialidad. Es así que nos encontramos en su filosofía con las nociones de información, cibernética, canal, técnica, entropía, neguentropía, diseño, fractales, hologramas, programas y pantalla. Si sumamos la "filosofía de la fotografía" (filosofia da caixa preta), la filosofía del diseño, la filosofía del canal y la filosofía de la pantalla, nos encontramos con una destacada arqueología (archivos) de la comunicación, y, además, con una poderosa filosofía de la comunicación, muy diferente al pensamiento tranquilizador y consensual de Habermas.

La segunda ley de la termodinámica, las no cosas, los cambios espaciales que ponen en cuestionamiento los apriorísticos kantianos de tiempo y espacio, entre ellos, la tridimensionalidad desestabilizada por la nulo-dimensionalidad (o dimensión cero), los cambios en la codificación, la nueva imaginación, son algunos de los conceptos que atraviesan parte de su extensa obra y que adquieren actualidad para pensar la comunicación, desde una ontología de lo singular y del presente. Por su parte, su debate con Kant es implícito y explícito a lo largo de su obra. "Somos los auténticos maestros hechiceros, los genuinos diseñadores, y eso nos permite, ahora que ya le hemos ganado la mano a Dios, hacer oídos sordos a todo canto de sirena y a todo Immanuel Kant que proclame con voz melodiosa 
la cuestión de la realidad..." (Flusser, 2002, p. 45). Pero hay otros debates con la filosofía kantiana así como con el funcionalismo (fue uno de sus mayores críticos): "Entre el bien puro (el 'categórico'), que no es bueno para nada, y el bien aplicado ('funcional'), en el fondo no puede haber compromiso ninguno, porque, en último término, todo aquello para lo que es bueno el bien aplicado, es, categóricamente, malo" (Flusser, 2002, p. 40).

La transición de la cultura del texto a la cultura de la imagen está acompañada del pasaje de la sociedad industrial a la postindustrial, de la historia a la posthistoria, de la materia a la postmateria, de la letra al número, de lo analógico a lo digital. Es decir, de la cultura lineal de la historia (centrada en la escritura) a la nulodimensionalidad y circularidad de la magia posthistórica. Del trabajo al juego, un juego macabro: "El nuevo ser humano ha dejado de ser un actuante, para convertirse en un jugador: un homo ludens, ya no un homo faber. Su vida ya no es un drama, sino un espectáculo. No tiene argumento, no tiene acción, sino que consiste en sensaciones" (Flusser, 2002, p. 107). Hay una vecindad en Flusser con la el fin de la historia -más leído a partir de la traducción de Hegel por parte de Kojéve en Francia-post-hegeliano, no obstante, es asumido como catástrofes que producen choques discontinuos. Si la mirada mágica es la primera edad de la imagen, y el arte, transformado en estética, la segunda, en la edad visual se retorna a la magia posthistórica.

A diferencia de muchas teorías sobre la escritura que consideran que desde la primera oralidad- mágica se pasó a la escritura- lineal, "etnocéntrica, logocéntrica", en términos de Jacques Derrida (1971), donde Occidente se convirtió en el reducto donde nace, se desarrolla y consolida la historia, Flusser fractura esas posiciones lineales, evolucionistas, y, plantea la idea de quiebre, "catástrofes" y "crisis" de esos estadios en los que se produjeron diversas mutaciones culturales. No venimos, pacífica y evolutivamente, de una oralidad "prehistórica" primigenia y, pasando por la escritura de la historia, nos conducimos a la tecnocéntrica posthistoria digital, en una línea ascendente que nos conduce al progreso, sino que hemos atravesado tres catástrofes y mutaciones. Hoy, nos encontramos, en la tercera de esas catástrofes.

\section{Flusser y la teoría de la imagen técnica}

La teoría de la imagen ha estado centrada en considerar a la imagen como soporte visual, sin embargo, hay carencias en problematizar la concepción de la imagen, abarcando otras áreas, como el lenguaje, el cuerpo, los sonidos y la comunicación. En términos más generales, considerar a la imagen desde la teoría de la comunicación. En ese contexto, Vilém Flusser brinda bases teórico- conceptuales, en su amplia obra bibliográfica, para pensar la imagen e indagar en ella, sin reducirla a sus aspectos visuales.

Tanto en sus textos más tempranos, muy inspirados en la fenomenología del lenguaje de base wittgenstenianas, como en su obra posterior, donde analiza la imagen como 
tecno-imagen, Flusser es consciente de que el propio concepto de imagen es limitado para referirse a campos más amplios y problemáticos. Flusser, al respecto, aclara que en la era post-histórica, sucesora de la historia y de la escritura, las nuevas imágenes no ocupan el mismo nivel ontológico que las imágenes tradicionales, porque son fenómenos sin paralelo en el pasado (Flusser, 2008, p. 13).

El concepto de imagen, $y$, fundamentalmente, de imagen técnica o tecno-imagen, se vincula, además, a la idea de pérdida de materialidad y de dimensionalidad. La cero-dimensionalidad da cuenta de esa carencia de sustento material y de dimensiones del espacio. También, se incorpora el elogio de la superficialidad de las imágenes técnicas, y de imaginar, como concretizar lo abstracto. En términos de Flusser (2008, p. 142) es la técnica como elogio de la superficialidad, es la miniaturización del universo, la superación de lo público y de lo privado, esto es, el fin de la política en el sentido que se consideraba en la época de la representación. La era de la posthistoria y de los aparatos, pone en cuestionamiento, además, el aura de la obra de arte y la pérdida anunciada por Benjamin.

En resumen, a partir del planteamiento teórico de Vilém Flusser, el concepto de imagen, se presenta como superficie, como el entremedio entre los espacios de lo visible y no visible, o cajas negras.

Al respecto, el concepto de caja negra, reducido a la filosofía de la fotografía en su edición española, brinda novedosas bases conceptuales para pesquisar sobre teoría de la imagen. La edición brasileña de febrero de 2011, corrige ese equívoco. En la presentación, Norval Baitello jr.(2011, p. 7), aclara que no es un libro sobre fotografía, y, el propio Flusser aclara en su prefacio de la primera edición brasileña, de octubre de 1985, que toma como pretexto la fotografía. Eso sí, contribuye a ampliar la filosofía sobre el aparato. La cuestión central es el aparato, porque el mundo actual vive en función del aparato.

La filosofía de la caja negra (filosofia da caixa preta) se refiere a las mediaciones como generadoras de ambientes. A los aparatos los siguen los funcionarios, que, en la actualidad, operan con aparatos minuciosamente programados.

Filosofia da caixa preta, es un texto fundamental, en la extensa obra de Flusser, ya que, como indica Baitello, desde ese momento el teórico conquistó definitivamente las miradas vigilantes de la vieja Europa, después de veinte años de insistentes tentativas de publicación de sus obras en suelo europeo. También, es un texto clave en su obra, ya que con la fotografía se inaugura un nuevo tipo de imagen, la imagen técnica o tecno- imagen. El aparato fotográfico, para Flusser, es el primero, el más simple y relativamente más transparente de todos los aparatos. El fotógrafo es el primer funcionario, el más ingenuo y más viable de ser analizado.

La continuación de la pesquisa de Flusser seguirá con $O$ universo das imagens técnicas, donde incorpora la idea de superficialidad, es decir, la pantalla elogia la superficialidad. En este tramo de su obra, continuará desarrollando las bases conceptuales de las tecno imágenes y su consecuencias (imaginar; abstraer; concretizar; apuntar; circular; dispersar; programar; jugar; etc...). 


\section{Debate en torno a la estética y a la política en los posthegelianos y los postkantianos}

Los intermedios y posteriores, planteamientos críticos en crisis, deconstructivos, fundamentalmente, en el caso de Derrida, desestabilizan y tensionan el planteamiento estético desde los márgenes (párergon) y la pregunta por "la verdad" de lo visual. La postestética, tanto en Badiou como en Rancière, se pregunta en un caso (Badiou) por lo inestético y, en el otro (Rancière), por el reparto de lo sensible. En el caso de Ranciére, siguiendo una estela más de corte postkantiano, iniciado, entre otros por Foucault, el reparto de lo sensible se concibe desde un a priori, que tiene sus vecindades con el a priori arqueológico foucaultiano (presente, tanto, en Las palabras y las cosas como en La Arqueología del saber). Si en Foucault el a priori de los archivos se presenta como una estructura discursiva y no discursiva (o visible) donde se estructuran las relaciones de poder-saber, en Jacques Ranciére, "Ios actos estéticos como configuraciones de la experiencia (...) dan cabida a modos nuevos del sentir e inducen formas nuevas de la subjetividad política" (Ranciére, 2009, p. 5). La relación entre estética y política, "si nos apegamos a la analogía podemos entenderla en un sentido kantiano - eventualmente revisitado por Foucault - como el sistema de formas a priori que determinan lo que se da a sentir. Es un recorte de tiempos y espacios, de lo visible y de lo invisible, de la palabra y el ruido que define a la vez el lugar y la problemática de la política como forma de experiencia". Una ontología de lo singular y del presente (en el sentido en que presenta en “¿qué es la ilustración?" de Kant) frente a una filosofía de la historia.

\section{Conclusiones: hacia una teoría de la pantalla.}

El giro estético de la ilustración no solo fue un giro en el arte y en la filosofía, sino que implicó un proceso de transformación de las relaciones entre estética y política y entre arte y política. La superación del arte, planteada por los situacionistas, se sostiene, en términos teóricos, en la filosofía hegeliana, un posthegelianismo de izquierdas que ya había tenido sus antecedentes en el Instituto de Investigaciones Sociales. En el caso de la comunicación, para pensar las tensiones entre técnica, imagen y estética, hay que repensar tanto las categorías kantianas como el concepto de estética que subyace a Hegel. Para ello, se requiere de un pensamiento aporético, que asuma la implicancia de la imagen técnica que, desde la aporía de lo superficial y lo profundo, permitan delinear los trazos de una teoría de la pantalla.

Victor Echeto es postdoctorado por la Universidad de Valencia, doctor en Estudios Culturales: Literatura y Comunicación por la Universidad de Sevilla e investigador del Centro de Estudios Avanzados de la Universidad de Playa Ancha de Chile.

vsilva@upla.cl 


\section{Referencias}

DEBORD, Guy. La sociedad del espectáculo. Valencia: Pre-textos, 1988.

DERRIDA, Jacques. De la gramatología. México (DF): siglo XXI,1971.

. "Firma, acontecimiento y contexto" en Márgenes de la filosofía. Madrid: Cátedra, 1989.

FOUCAULT, Michel. “¿Qué es la crítica? Crítica y Aufklärung” en Sobre la ilustración. Madrid: Tecnos, 2006.

La arqueología del saber. México (DF): siglo XXI, 1996.

. Las palabras y las cosas. México (DF): Siglo XXI, 1986.

HORKHEIMER, Max. "Teoría tradicional y teoría crítica" en Teoría crítica. Buenos Aires: Amorrortu, 1974.

FLUSSER, Vilém. Los gestos. Fenomenología y comunicación. Barcelona: Herder, 1994.

Una filosofía de la fotografía. Madrid: Síntesis, 2001.

Filosofía del diseño. Madrid: Síntesis, 2002.

Da Religiosidade. A literatura e o senso da realidade. São Paulo: escrituras, 2002 b.

. "La apariencia digital" en Gerardo Yoel Pensar el cine 2. Buenos Aires: Manantial, 2004.

. "La sociedad alfanumérica" en Revista Austral de Ciencias Sociales, n 9, 2005.

O mundo codificado. Sao Paulo: Cosac Naify, 2007.

. O universo das imagens técnicas. Elogio da superficialidade. São Paulo: Annablume, 2008.

JAY, Martin. A imaginação dialéctica. História da Escola de Frankfurt e do Instituto de Pesquisas Sociais, 1923- 1950. Río de Janeiro: Contraponto, 2008.

KANT, Immanuel. Crítica del juicio. Buenos Aires: Losada, 1993.

RANCIÈRE, Jacques. El reparto de lo sensible. Santiago (Chile): Lom, 2009. 